\title{
Selected nutritional biomarkers predict diet quality
}

\author{
Marian L Neuhouser ${ }^{1}$ * , Ruth E Patterson ${ }^{1,2}$, Irena B King ${ }^{1}$, Neilann K Horner ${ }^{1}$ and \\ Johanna W Lampe ${ }^{1,2}$ \\ ${ }^{1}$ Cancer Prevention, Fred Hutchinson Cancer Research Center, 1100 Fairview Avenue North, POB 19024, \\ MP-702, Seattle, WA 98109-1024, USA: ${ }^{2}$ Department of Epidemiology and Program in Nutritional Sciences, \\ School of Public Health and Community Medicine, University of Washington, Seattle, WA, USA
}

Submitted 2 August 2002: Accepted 7 May 2003

\begin{abstract}
Objective: To examine associations of biomarkers of nutrient intake with overall diet quality.

Subjects: A convenience sample of 102 healthy postmenopausal women in Seattle, Washington (USA).

Design and method: Participants attended a study centre where they provided fasting blood specimens and completed a 122-item validated food-frequency questionnaire (FFQ). Data from the FFQ were used to calculate Diet Quality Index (DQI) scores and categorise women as having diets of excellent, good, fair or poor quality. The blood specimens were analysed for nine phospholipid fatty acids (as percentage of total) and serum concentrations of vitamin $C, \alpha$-tocopherol, $\gamma$-tocopherol, vitamin $B_{12}$, folate and six carotenoids. Multivariate linear regression was used to model associations of the nutrient biomarkers with DQI scores.

Results: Compared with women with poor-quality diets, women with excellent diets, as measured by the DQI, had higher plasma concentrations of vitamin C ( $P$ for trend $=0.01), \alpha$-tocopherol $(P$ for trend $=0.02)$ and $\beta$-cryptoxanthin ( $P$ for trend $=0.03$ ). Women with excellent diets also had lower proportions of plasma phospholipid fatty acids of two potentially atherogenic fatty acids: stearic acid ( $P$ for trend $=0.01$ ) and behenic acid $(P$ for trend $=0.03$ ). A group of six biomarkers explained a moderate proportion of the total variability in DQI scores (36\%).

Conclusions: These objective measures of dietary intake support the use of the DQI as a useful tool to measure dietary patterns.
\end{abstract}

In the past 10 years, considerable research has focused on the development and use of indices of overall diet quality. A number of related approaches have been proposed, including the Diet Diversity Score ${ }^{1}$, the Diet Quality Index ${ }^{2}$ and the Healthy Eating Index ${ }^{3}$. All of these indices sum across a number of foods (e.g. servings of fruits and vegetables) and/or nutrient measures (e.g. percentage energy from fat) to calculate a single score that ranks an individual on their overall diet quality.

These global indices of food and nutrient intake have a number of useful properties. From a health perspective, it is clear that a good diet is the sum total of food choices, as opposed to a single food or nutrient. Therefore, an index that reflects overall diet quality is, conceptually, an important exposure for research on diet and health ${ }^{4}$. Ranking individuals by diet quality may offer important clues about disease risk, which could be applied to programmes for prevention ${ }^{5}$. Kant et al. found that an overall score based on recommended food consumption guidelines was significantly inversely associated with all-cause mortality in 42454 women participating in the Breast Cancer Detection Demonstration Project ${ }^{6}$. McCullough et al. reported that the Healthy Eating Index was not associated with overall risk of major chronic disease, but was associated with a non-statistically significant $14 \%$ reduction in cardiovascular disease risk in the Nurses' Health Study ${ }^{7}$.

To better understand the potential utility of measures of overall diet with nutritional status and health, this report compares the Diet Quality Index (DQI) scores of postmenopausal women with a varied array of nutritional biomarkers. Specifically, we examine the following biomarkers: (1) phospholipid fatty acids associated with intake of animal products and nuts (stearic, palmitic and behenic acids), plant sources of fat such as olive oil (oleic and palmitoleic acids), fish consumption (eicosapentaenoic acid (EPA) and docosahexaenoic acid (DHA)), and margarine and processed foods (trans fatty acids); 
(2) vitamins associated with meat and dairy intake (vitamin $\mathrm{B}_{12}$ ), corn/soybean oils and fortified foods ( $\alpha$ - and $\gamma$-tocopherol), and fruits and vegetables (vitamin $C$, folate); and (3) bioactive compounds associated with fruit and vegetable intake (carotenoids). Data relating a diet quality score with biomarkers can give information on objective measures of intake in relation to dietary patterns and provide insight into mechanisms by which eating patterns may influence disease occurrence.

\section{Methods}

\section{Study participants}

We recruited a convenience sample of postmenopausal women aged 50-79 years in Seattle, WA, USA. Potential participants were screened via a telephone-administered eligibility-screening interview for conditions that might interfere with biomarker measurements, such as bowel disease, diabetes, renal disease and liver disease. Of the 177 women who completed the telephone screening, 102 (57.6\%) were recruited and completed all study procedures. The Institutional Review Board at the Fred Hutchinson Cancer Research Center approved all procedures and all participants signed informed consent.

\section{Measures}

Participants attended two visits to a study centre, one week apart, where they completed a variety of procedures and provided two fasting blood samples. Procedures and data collection relevant to the analyses presented in this report are described below.

\section{Blood collection, processing and analysis}

Participants arrived at the study centre for both visits after an overnight fast $(\geq 8 \mathrm{~h})$ and phlebotomists collected blood samples into serum and plasma separating tubes, which were protected from heat and light throughout processing and storage. Plasma aliquots for vitamin C (ascorbic acid) analysis were preserved with metaphosphoric acid/dithiothretol solution. All specimens were stored at $-70^{\circ} \mathrm{C}$ until analysis at the Core Laboratory of the Fred Hutchinson Cancer Research Center. The carotenoids, $\alpha$-tocopherol and $\gamma$-tocopherol were analysed with high-performance liquid chromatography after biphasic extraction as previously described ${ }^{8,9}$. Vitamin C and total serum cholesterol were measured with enzymatic procedures on a Cobas Mira Plus chemistry analyser (Roche, Branchburg, NJ, USA) ${ }^{10}$. Serum folate and vitamin $B_{12}$ were analysed by radioimmunoassay using the Quantaphase II radioassay kit (Bio-Rad Laboratories, Inc., Hercules, CA, USA) ${ }^{11,12}$. Phospholipid fatty acids were analysed utilising Folch extraction and thin layer and gas chromatographies for separation and quantification $^{13}$, and are expressed as weight percentage of the total fatty acids ${ }^{14}$. The coefficients of variation for the measured analytes were: $<6 \%$ for ascorbic acid;
$<10 \%$ for folate and $\mathrm{B}_{12} ;<3.5 \%$ for total cholesterol; $<2 \%$ for $\alpha$ - and $\gamma$-tocopherol; $<3.5 \%$ for $\alpha$-carotene, $\beta$-carotene and lycopene; $<3.9 \%$ for lutein; $<4.1 \%$ for zeaxanthin; and $<1.3 \%$ for $\beta$-cryptoxanthin; all fatty acids were $<5 \%$. The mean of the duplicate blood measures was used in all analyses.

\section{Dietary assessment}

Prior to each study visit, participants completed the Women's Health Initiative food-frequency questionnaire $(\mathrm{FFQ})^{15}$. This FFQ asks about usual dietary intake over the previous three months of 122 foods or food groups, with questions on usual frequency of intake and portion size. We analysed the dietary data using the University of Minnesota, Nutrition Coordinating Center Nutrient Database $^{16}$ and details regarding our procedures for analysis have been published elsewhere ${ }^{15,17}$. Participants who used dietary supplements were asked to bring all bottles to each clinic visit where use was assessed with a validated inventory procedure ${ }^{18}$.

\section{Diet Quality Index}

Diet quality was measured with a composite score of overall healthfulness called the Diet Quality Index (DQI) ${ }^{2}$. The DQI reflects an individual's adherence to the eight Diet and Health recommendations of the National Academy of Sciences (reduce total fat intake to 30\% or less of energy; reduce saturated fat intake to less than $10 \%$ of energy; reduce cholesterol to less than $300 \mathrm{mg} \mathrm{day}^{-1}$; eat five or more servings of fruits and vegetables per day; eat six or more servings of breads, cereals and legumes per day; maintain protein intake at moderate levels; limit sodium to less than $2400 \mathrm{mg} \mathrm{day}^{-1}$; and maintain adequate calcium intake) ${ }^{19}$. Due to the analytical complexity of measuring servings of grains from an FFQ, these analyses used grams of fibre $/ 1000 \mathrm{kcal}$ as a proxy measure for servings of grains, cereals and legumes ${ }^{20}$. The mean estimates of nutrient intake from the duplicate FFQs were used to score participants for each of the eight recommendations based on a previously published algorithm ${ }^{2}$. The score was ' 0 ' if participants met a given recommendation, ' 1 ' if their consumption was within $30 \%$ of a recommendation and ' 2 ' if their consumption differed by more than $30 \%$ of a recommendation. Scores for the eight recommendations were summed to give a total DQI score (range $0-16)$, with a lower score $(\leq 5)$ indicative of a healthful $\operatorname{diet}^{2}$.

\section{Anthropometry}

We measured height and weight at each clinic visit. Body mass index was calculated as weight (in $\mathrm{kg}$ ) divided by the square of height (in $\mathrm{m}$ ).

\section{Other measures}

We collected demographic data using a self-administered questionnaire. 


\section{Data analysis}

Multivariate linear regression models were used to examine associations of nutrient biomarkers with diet quality. These analyses used the concentrations of the serum or plasma nutrients as the independent variables and the DQI scores as the dependent variables and included a linear contrast to test for trends. Duncan's multiple range test was used to test for multiple comparisons. The selected biomarkers represent some, but not all, aspects of the DQI since there are not suitable biomarkers for some DQI components (i.e. fibre). All serum nutrient concentrations were $\log _{\mathrm{e}}$-transformed prior to analysis to improve normality and results were back-transformed and presented in original units for ease of interpretation. All models included age, body mass index and dietary supplement use as potential confounding variables, and models with lipid-soluble nutrients (e.g. fatty acids, $\alpha$-tocopherol, $\gamma$-tocopherol and the carotenoids) included additional adjustments for total serum cholesterol. We examined the contribution of energy intake to these models, but because energy was neither statistically significant nor influential on mean biomarker concentrations, energy was not included in the final models. Stepwise regression was used to estimate which biomarkers were the best predictors of the DQI; variables were retained in the model if $P \leq 0.10$. All statistical analyses were conducted with SAS, version 8.2 (SAS Institute, Cary, NC, USA).

\section{Results}

The mean age of study participants was 61.4 years, $94.2 \%$ of the sample was Caucasian, $61.8 \%$ had a college degree or higher and $51.6 \%$ had an annual household income in excess of $\$ 50000$. Over half of the study participants were overweight $(34.3 \%)$ or obese $(21.6 \%)^{21}$, and $81 \%$ used a dietary supplement at least once a week. Women who had excellent diets were more likely to be users of vitamin $\mathrm{E}$ supplements, but there were no other associations of diet quality with dietary supplement use (data not shown). Table 1 gives the distributions of the nutritional biomarkers.

Table 2 gives associations of nutrient biomarkers with the DQI scores. Only $15.7 \%$ of the women had excellent diets (score $\leq 5$ ) that adhered to the Diet and Health recommendations. Thirty per cent and $38.2 \%$ of participants had a good (DQI $=6-7$ ) or fair (DQI $=8-10)$ diet, respectively, and $16.7 \%$ had high DQI scores $(\geq 11)$ indicative of a poor diet. There were positive associations of monounsaturated fatty acid concentrations with a healthful diet. Specifically, plasma oleic acid was higher among women with an excellent diet compared with those with a poor diet $(P$ for trend $=0.09)$. Two saturated fatty acids, stearic acid and behenic acid, were significantly lower among women with excellent or good diets compared with those with poor-quality diets. In contrast,
Table 1 Distributions of nutritional biomarkers in the sample of postmenopausal women $(n=102)$

\begin{tabular}{|c|c|c|}
\hline Blood analyte & Mean* & $\begin{array}{l}\text { Standard } \\
\text { deviation }\end{array}$ \\
\hline \multicolumn{3}{|l|}{ Fatty acids } \\
\hline Myristic acid (14:0) (\%) & 0.37 & 0.02 \\
\hline Palmitic acid (16:0) (\%) & 25.8 & 1.55 \\
\hline Palmitoleic acid $(16: 1 n-7)(\%)$ & 0.65 & 0.09 \\
\hline Stearic acid (18:0) (\%) & 12.6 & 1.1 \\
\hline Oleic acid $(18: 1 n-9)(\%)$ & 8.11 & 1.0 \\
\hline Trans isomers (18:1) (\%) & 1.28 & 0.22 \\
\hline Behenic acid (22:0) (\%) & 1.63 & 0.18 \\
\hline Eicosapentaenoic acid $(20: 5 n-3)(\%)$ & 0.93 & 0.21 \\
\hline Docosahexaenoic acid $(22: 6 n-3)(\%)$ & 3.77 & 0.85 \\
\hline \multicolumn{3}{|l|}{ Vitamins } \\
\hline Vitamin $\mathrm{C}\left(\mu \mathrm{mol} \mathrm{I}^{-1}\right)$ & 67.7 & 8.7 \\
\hline$\alpha$-Tocopherol $\left(\mu \mathrm{moll}^{-1}\right)$ & 42.2 & 13.5 \\
\hline$\gamma$-Tocopherol $\left(\mu \mathrm{moll}^{-1}\right)$ & 2.35 & 0.81 \\
\hline Folate $\left(\mathrm{nmoll} \mathrm{I}^{-1}\right)$ & 59.1 & 23.0 \\
\hline Vitamin $\mathrm{B}_{12}\left(\mathrm{pmoll}^{-1}\right)$ & 429 & 183 \\
\hline \multicolumn{3}{|l|}{ Carotenoids } \\
\hline$\alpha$-Carotene $\left(\mu \mathrm{moll}^{-1}\right)$ & 0.19 & 0.02 \\
\hline$\beta$-Carotene $\left(\mu \mathrm{moll}^{-1}\right)$ & 0.85 & 0.20 \\
\hline$\beta$-Cryptoxanthin $\left(\mu \mathrm{moll}^{-1}\right)$ & 0.25 & 0.02 \\
\hline Lycopene $\left(\mu \mathrm{moll}{ }^{-1}\right)$ & 0.78 & 0.10 \\
\hline Lutein plus zeaxanthin $\left(\mu \mathrm{moll} \mathrm{I}^{-1}\right)$ & 0.44 & 0.03 \\
\hline
\end{tabular}

* Geometric means.

palmitic acid was significantly higher among women with excellent and good diets compared with women with poor diets $(P$ for trend $=0.01$ ), while the plasma phospholipid myristic acid was relatively constant across DQI scores.

Plasma vitamin $\mathrm{C}$ was higher among women with an excellent or good diet than in those with a fair or poor diet ( $P$ for trend $=0.01$ ). Women with an excellent or good diet had higher serum $\alpha$-tocopherol concentrations than women with a fair or poor diet $(P$ for trend $=0.02$ ). We attribute this finding to more frequent use of single supplements of vitamin $\mathrm{E}$ (which is exclusively $\alpha$-tocopherol) by women with excellent or good diets, compared with women with fair or poor diets $(P=0.07)$ (data not shown). In contrast, serum $\gamma$-tocopherol (the predominant form of vitamin $\mathrm{E}$ in dietary fats and oils) was lower among participants with an excellent or good diet compared with those with a fair or poor diet $(P$ for trend $=0.09$ ). Higher serum vitamin $\mathrm{B}_{12}$ concentration was associated with excellent or good diet quality ( $P$ for trend $=0.05$ ).

Of the five circulating serum carotenoid concentrations, only $\beta$-cryptoxanthin was significantly associated with diet quality. Participants with an excellent diet had higher serum $\beta$-cryptoxanthin concentrations than those with good and fair or poor diets, respectively ( $P$ for trend $=0.03$ ).

Six of the 19 biomarkers explained $36 \%$ of the variance in the DQI scores in a stepwise regression model (Table 3 ). These nutrient biomarkers included two vitamins (vitamins $\mathrm{C}$ and $\mathrm{E}$ ), two fatty acids (oleic acid and stearic acid) and two carotenoids ( $\alpha$-carotene and $\beta$-cryptoxanthin). Plasma vitamin $\mathrm{C}$ had the strongest influence on the DQI, explaining $16 \%$ of the variance. 
Table 2 Associations of nutritional biomarkers with the Diet Quality Index (DQI) in 102 postmenopausal women

\begin{tabular}{|c|c|c|c|c|c|}
\hline \multirow[b]{2}{*}{ Blood analyte } & \multicolumn{4}{|c|}{$\begin{array}{l}\text { Mean concentration* } \dagger \\
\text { across DQI scores }\end{array}$} & \multirow[b]{2}{*}{$\begin{array}{c}P \\
\text { for trend }\end{array}$} \\
\hline & $\begin{array}{c}\text { Score }=1-5 \\
\text { excellent diet } \\
\quad(n=16)\end{array}$ & $\begin{array}{c}\text { Score }=6-7 \\
\text { good diet } \\
(n=30)\end{array}$ & $\begin{array}{c}\text { Score }=8-10 \\
\quad \text { fair diet } \\
(n=39)\end{array}$ & $\begin{array}{l}\text { Score }=11-16 \\
\text { poor diet } \\
(n=17)\end{array}$ & \\
\hline \multicolumn{6}{|l|}{ Fatty acids } \\
\hline Myristic acid (14:0) (\%) & 0.35 & 0.38 & 0.38 & 0.38 & 0.78 \\
\hline Palmitic acid (16:0) (\%) & $26.4^{\mathrm{a}}$ & $26.2^{\mathrm{a}}$ & $25.9^{\mathrm{a}, \mathrm{b}}$ & $24.9^{\mathrm{b}}$ & 0.01 \\
\hline $\begin{array}{l}\text { Palmitoleic acid } \\
(16: 1 n-7)(\%)\end{array}$ & 0.68 & 0.71 & 0.62 & 0.60 & 0.08 \\
\hline Stearic acid (18:0) (\%) & $12.2^{\mathrm{a}}$ & $12.4^{\mathrm{a}}$ & $12.6^{\mathrm{a}}$ & $13.5^{\mathrm{b}}$ & 0.01 \\
\hline Oleic acid $(18: 1 n-9)(\%)$ & $8.58^{\mathrm{a}}$ & $8.13^{\mathrm{a}, \mathrm{b}}$ & $8.11^{\mathrm{a}, \mathrm{b}}$ & $7.52^{\mathrm{b}}$ & 0.09 \\
\hline Trans isomers $(18: 1)(\%)$ & 1.31 & 1.22 & 1.28 & 1.35 & 0.85 \\
\hline Behenic acid (22:0) (\%) & $1.55^{\mathrm{a}}$ & $1.57^{\mathrm{a}}$ & $1.65^{\mathrm{a}, \mathrm{b}}$ & $1.79^{\mathrm{b}}$ & 0.03 \\
\hline $\begin{array}{l}\text { Eicosapentaenoic acid } \\
(20: 5 n-3)(\%)\end{array}$ & 0.87 & 1.03 & 0.89 & 0.91 & 0.98 \\
\hline $\begin{array}{l}\text { Docosahexaenoic acid } \\
(22: 6 n-3)(\%)\end{array}$ & 3.86 & 3.81 & 3.77 & 3.74 & 0.78 \\
\hline \multicolumn{6}{|l|}{ Vitamins } \\
\hline Vitamin $C\left(\mu \mathrm{moll}^{-1}\right)$ & $72.1^{\mathrm{a}}$ & $73.2^{\mathrm{a}}$ & $65.9^{\mathrm{a}, \mathrm{b}}$ & $57.9^{\mathrm{b}}$ & 0.01 \\
\hline$\alpha$-Tocopherol $\left(\mu \mathrm{mol} \mathrm{I}^{-1}\right)$ & $45.5^{\mathrm{a}, \mathrm{b}}$ & $47.1^{\mathrm{a}}$ & $38.5^{\mathrm{b}}$ & $40.1^{\mathrm{a}, \mathrm{b}}$ & 0.02 \\
\hline$\gamma$-Tocopherol $\left(\mu \mathrm{moll}^{-1}\right)$ & $1.73^{\mathrm{a}}$ & $1.94^{\mathrm{a}, \mathrm{b}}$ & $2.66^{b, c}$ & $2.95^{\mathrm{c}}$ & 0.09 \\
\hline Folate $\left(\mathrm{nmolI} \mathrm{I}^{-1}\right)$ & $64.4^{\mathrm{a}, \mathrm{b}}$ & $69.6^{\mathrm{a}}$ & $58.2^{\mathrm{a}, \mathrm{b}}$ & $54.1^{\mathrm{b}}$ & 0.18 \\
\hline Vitamin $\mathrm{B}_{12}\left(\mathrm{pmoll}^{-1}\right)$ & 339 & 341 & 310 & 270 & 0.05 \\
\hline \multicolumn{6}{|l|}{ Carotenoids } \\
\hline$\alpha$-Carotene $\left(\mu \mathrm{moll}^{-1}\right)$ & 0.22 & 0.19 & 0.19 & 0.17 & 0.46 \\
\hline$\beta$-Carotene $\left(\mu \mathrm{moll}^{-1}\right)$ & 0.82 & 0.95 & 0.84 & 0.73 & 0.72 \\
\hline$\beta$-Cryptoxanthin $\left(\mu \mathrm{moll}^{-1}\right)$ & $0.34^{\mathrm{a}}$ & $0.25^{\mathrm{b}}$ & $0.22^{\mathrm{b}}$ & $0.22^{b}$ & 0.03 \\
\hline Lycopene $\left(\mu \mathrm{moll}^{-1}\right)$ & 0.78 & 0.73 & 0.78 & 0.89 & 0.34 \\
\hline $\begin{array}{l}\text { Lutein plus zeaxanthin } \\
\left(\mu \mathrm{mol} \mathrm{I}^{-1}\right)\end{array}$ & 0.50 & 0.48 & 0.45 & 0.43 & 0.76 \\
\hline
\end{tabular}

${ }^{*}$ All means are adjusted for age, body mass index and dietary supplement use. Fatty acids, $\alpha$-tocopherol, $\gamma$-tocopherol and the carotenoids include additional adjustment for total serum cholesterol.

† Means with different superscript letters vary significantly across DQI scores.

\section{Discussion}

In this sample of healthy postmenopausal women, biomarkers of healthful food choices were associated with better DQI scores, while biomarkers of less healthful choices were associated with poorer DQI scores. For example, plasma phospholipid fatty acids derived from peanuts and animal products ${ }^{22,23}$ and $\gamma$-tocopherol found in mayonnaise, salad dressings, fried foods and manufactured baked goods ${ }^{24}$ were significantly lower among women with good or excellent diets compared with those with fair or poor diets. Two saturated fatty acids that have

Table 3 Stepwise regression analysis of biomarkers and the Diet Quality Index (DQI) in 102 postmenopausal women*

\begin{tabular}{lccc}
\hline Biomarker & $\begin{array}{c}\text { Parameter } \\
\text { estimate }(\beta)\end{array}$ & $P$-value & $R^{2}$ \\
\hline Vitamin $\mathrm{C}\left(\mu \mathrm{molI}^{-1}\right)$ & -4.52 & $<0.001$ & 0.16 \\
$\alpha$-Tocopherol $\left(\mu \mathrm{moll}^{-1}\right)$ & -1.59 & 0.07 & 0.03 \\
$\alpha$-Carotene $\left(\mu \mathrm{mol}{ }^{-1}\right)$ & -7.88 & 0.07 & 0.03 \\
$\beta$-Cryptoxanthin $\left(\mu \mathrm{mol}^{-1}\right)$ & -7.34 & 0.01 & 0.05 \\
Oleic acid $(\%)$ & -4.74 & 0.09 & 0.02 \\
Stearic acid $(\%)$ & 8.73 & 0.005 & 0.07 \\
Total variance explained $\left(R^{2}\right)$ & & & 0.36 \\
\hline
\end{tabular}

${ }^{*} \mathrm{DQI}$ scores range from 1 to 16 , with a lower score indicative of a healthful diet. been associated with increased risk of coronary heart disease, stearic $\operatorname{acid}^{25}$ and behenic acid ${ }^{26}$, were significantly lower among women with good or excellent DQI scores than among those with poor diet quality. Likewise, our results showed that numerous compounds with presumed beneficial properties, including phospholipid monounsaturated fatty acids and serum concentrations of vitamin $\mathrm{C}, \beta$-cryptoxanthin, folate and $\alpha$-tocopherol, were higher among women with good or excellent diets compared with those with fair or poor diets. A subset of these nutritional biomarkers (six of 19) explained 36\% of the variance in DQI scores. This finding is notable, given that demographic (i.e. age, sex, race/ethnicity) and lifestyle (i.e. exercise, body mass index) predictors of diet typically explain only a small proportion $(<10 \%)$ of variance in models predicting percentage energy from fat or fruit and vegetable intake ${ }^{27-29}$.

We found that palmitic acid, which may raise serum low-density lipoprotein (LDL) concentrations ${ }^{30}$, was significantly higher in women with excellent or good diets, compared with those with poor diets. These findings are in agreement with a controlled feeding study showing that when participants consumed a low-fat diet (20\% of energy from fat), there was a significant increase in palmitic acid incorporated in plasma phospholipids, compared with measures taken following a high-fat diet 
( $45 \%$ of energy as fat $)^{22}$. These results are not unexpected, since de novo synthesis of palmitic acid is up-regulated by a low-fat, high-carbohydrate diet. An additional explanation for elevation of this saturated fatty acid in relation to an excellent dietary pattern is that metabolic factors independent of macronutrient intake influence incorporation of fatty acids into the phospholipid fraction.

Few other studies have examined diet quality indices as they relate to biological markers of intake or disease risk. Hann et al. reported significant associations of better Healthy Eating Index scores with higher serum concentrations of folate, ascorbic acid and all carotenoids except lycopene ${ }^{31}$. Fung and colleagues showed that a Western dietary pattern, which is characterised by high intakes of red meat, sweets, and fried and processed foods, was positively associated with biomarkers of elevated disease risk, such as elevated serum homocysteine, C-peptide and leptin ${ }^{32}$. Gerber et al. tested the associations of selected biomarkers with a modified $\mathrm{DQI}^{33}$. Similar to our results, they found no differences in mean $\beta$-carotene concentrations across the DQI scores. Gerber et al. also found that the marine fatty acids, EPA and DHA, were significantly higher among participants with excellent diets, compared with those with fair or poor diets, whereas we found no associations of these types of fatty acid with DQI score. Variations in fish consumption patterns between subjects in southern France and our sample of postmenopausal women in Seattle may explain these differences in results.

This study has a number of strengths. First, we used a panel of 19 biomarkers that reflect both healthful and unfavourable dietary patterns, in contrast to other studies that have generally focused on limited groups of markers (e.g. compounds in fruits and vegetables, such as carotenoids). Second, the dietary assessment instrument used in this study has been validated previously in postmenopausal women and it appeared to perform well in this population ${ }^{15}$. Third, all of the women were healthy; thus, measurement of the biomarkers was unlikely to be affected by any disease process that could affect circulating nutrient concentrations. Fourth, we used the mean of duplicate measures for all dietary and blood data, thus reducing measurement error and improving precision $^{34}$.

Limitations should also be noted. The study sample was homogeneous, consisting of mostly Caucasian, well-educated women. Because some of the variability in the nutritional biomarkers measured here can be explained by demographic characteristics ${ }^{35,36}$, examination of these factors in a more heterogeneous sample would be important in future studies of this nature. While we did control for known confounders of the associations of diet with serum measures (i.e. age, body mass index), there may be additional unknown confounders that could obscure these relationships. In addition, much remains to be understood about the health effects of individual fatty acids. For example, while stearic acid does not raise LDL concentrations $^{37,38}$ it may be atherogenic via other mechanisms, such as increasing lipoprotein(a) or decreasing high-density lipoprotein ${ }^{25}$. Another limitation is that not all of the components of the DQI (i.e. grain/fibre intake) are represented by our group of nutritional biomarkers. Further, although de novo fatty acid synthesis comprises only a small portion of total fatty acids in plasma phospholipids, there is substantial desaturation and elongation of both endogenous and exogenous fatty acids. Thus, not all of the fatty acids we measured are exclusively of dietary origin. Finally, while the use of an array of biomarkers is a strength of this study, multiple tests have been conducted on a single dataset, which increases the possibility of a type I error. Therefore, readers should use caution in interpreting the $P$-values in this study.

Analytical challenges that relate to the use of nutritional biomarkers as objective measures of diet should be mentioned. A quandary in nutritional epidemiology is that most studies investigating the associations of diet with chronic disease risk rely on self-reported measures of diet. Even instruments that are considered a 'reference' or 'gold standard' measure include systematic bias and errors in all types of self-reported dietary assessment instruments (recalls, records, FFQs) are positively correlated ${ }^{39-42}$. This lack of independent errors violates the principles of the classical measurement model and limits conclusions that may be drawn from validation or calibration studies where two or more dietary assessment tools are typically used to estimate true intake ${ }^{41,42}$. For example, FFQs and 24-hour dietary recalls both rely on the participant's memory and misreporting of food intake is common ${ }^{42}$. Thus, the ability to measure food intake accurately in relation to disease risk is complicated by substantial measurement error when dietary assessment relies on self-report. For this reason, there is an emerging trend by nutritional epidemiologists to use biological indicators of dietary intake as an objective measure of diet. It is important to note that there are only two biomarkers that give a quantitative assessment of dietary intake and whose errors are truly independent of the errors in self-report (urinary nitrogen for protein intake and doubly labelled water for energy intake) ${ }^{42}$. The majority of nutritional biomarkers, including those used in the present study, are concentration-based biomarkers (i.e. vitamin C, folate and the carotenoids). Concentration-based nutritional biomarkers are responsive to dietary intake and generally follow a linear association with diet. They cannot be used to estimate absolute intake in the same manner as doubly labelled water or urinary nitrogen, but concentrationbased biomarkers can be used to help confirm data obtained by self-report from questionnaires ${ }^{43}$. For example, the findings presented in this study showed that women with low DQI scores (i.e. excellent diets) had 
higher serum concentrations of vitamins and compounds found in fruits and vegetables (i.e. $\beta$-cryptoxanthin) and smaller fractions of atherogenic-type fatty acids, compared with women with poor diets.

Despite the apparent objective nature of concentrationbased nutritional biomarkers, the errors in the biomarkers are not completely independent of the errors in selfreported measures of dietary intake. For example, measured concentrations of vitamins and carotenoids depend not only on recently consumed amounts in food, but also on personal characteristics and concurrently ingested foods and nutrients, some of which are often underreported by participants (i.e. fat and energy) $35,36,42,44$. As such, concentration-based nutritional biomarkers may not provide as objective information as one would like to believe. Still, they may offer some improvement over measures of self-report alone because a smaller fraction of the errors between the measures is likely to be correlated. For example, the concentration-based biomarkers are independent of a participant's memory and social desirability factors. Because it is not currently known whether self-reported dietary intake data or concentration biomarkers are more reliable correlates of true dietary intake, further research is clearly needed to address these important measurement issues and implications for studies of diet and chronic disease ${ }^{42}$.

It is important to note that the current study cannot be construed as a 'validation study', where these measurement error issues are often examined. Validity is the extent to which the 'truth' can be measured and the standard design of a dietary validation study includes comparison of the 'test measure' with a reference or 'gold standard' measure ${ }^{45}$. Because we did not include a 'gold standard' measure of diet or diet quality in these analyses, the biomarkers essentially serve as additional correlates of diet $^{43}$. Human feeding studies where the experimenter rigorously controls the participant's diet may be a particularly useful design to quantify better the association of concentration biomarkers with true dietary intake while avoiding the problems associated with self-report.

The use of dietary patterns to examine disease risk may be a more useful public health tool than reliance on analyses of single nutrients. This report shows that selected nutritional biomarkers predict DQI scores, supporting use of this assessment tool as a suitable measure of total diet, with potential applications for monitoring of disease risk.

\section{Acknowledgements}

This study was supported by the Fannie E Rippel Foundation, the Fred Hutchinson Cancer Research Center and NIH R03 CA 80648. The authors gratefully acknowledge Dr Ross L Prentice for his contributions to this project.

\section{References}

1 Kant AK, Schatzkin A, Ziegler RG. Dietary diversity and subsequent cause-specific mortality in the NHANES I epidemiologic follow-up study. Journal of the American College of Nutrition 1995; 14: 233-8.

2 Patterson RE, Haines PS, Popkin BM. Diet Quality Index: capturing a multidimensional behavior. Journal of the American Dietetic Association 1994; 94: 57-64.

3 Kennedy ET, Ohls J, Carlson S, Fleming K. The Healthy Eating Index: design and applications. Journal of the American Dietetic Association 1995; 95: 1103-8.

4 Kant AK. Indexes of overall diet quality: a review. Journal of the American Dietetic Association 1996; 96: 785-91.

5 Popkin BM, Siega-Riz AM, Haines PS. A comparison of dietary trends among racial and socioeconomic groups in the United States. New England Journal of Medicine 1996; 335: 716-20.

6 Kant AK, Schatzkin A, Graubard BI, Schairer C. A prospective study of diet quality and mortality in women. Journal of the American Medical Association 2000; 283: 2109-15.

7 McCullough ML, Feskanich D, Stampfer MJ, Rosner BA, Hu FB, Hunter DJ, et al. Adherence to the Dietary Guidelines for Americans and risk of major chronic disease in women. American Journal of Clinical Nutrition 2000; 72: 1223-31.

8 Zhang C, Williams MA, Sanchez SE, King IB, Ware-Jauregui $\mathrm{S}$, Larrabure $\mathrm{G}$, et al. Plasma concentrations of carotenoids, retinol and tocopherols in preelamptic and normotensive women. American Journal of Epidemiology 2001; 153 $572-80$.

9 Kalman DA, Goodman GE, Omenn GS, Bellamy G, Rollins B. Micronutrient assay for cancer prevention clinical trials: serum retinol, retinyl palmitate, alpha-carotene and betacarotene with the use of high-performance liquid chromatography. Journal of the National Cancer Institute 1987; 79 975-82.

10 Lee W, Roberts SM, Labbe RF. Ascorbic acid determination with an automated enzymatic procedure. Clinical Chemistry 1997; 43: 154-7.

11 Gunther EW, Bowman BA, Caudill SP, Twit DB, Adams MJ, Sampson EJ. Results of an international round robin for serum and whole blood folate. Clinical Chemistry 1996; 43 1689-94.

12 Rajkovic A, Mohamed K, Rozen R, Malinow MR, King IB, Williams MA. Methylenetetrahydrofolate reductase $667 \mathrm{C} \rightarrow \mathrm{T}$ polymorphism, plasma folate vitamin $\mathrm{B}_{12}$ concentrations and risk of preeclampsia among black African women from Zimbabwe. Molecular Genetics and Metabolism 2000; 69: 33-9.

13 Folch J, Lees M, Sloane GH. A simple method for isolation and purification of total lipids from animal tissues. Journal of Biological Chemistry 1957; 226: 497.

14 Satia JA, Patterson RE, Herrero R, Jin F, Dai Q, King IB, et al. Study of diet, biomarkers and cancer risk in the United States, China and Costa Rica. International Journal of Cancer 1999; 82: 28-32.

15 Patterson RE, Kristal AR, Tinker L, Carter RA, Bolton MP, Agurs-Collins T. Measurement characteristics of the Women's Health Initiative food frequency questionnaire. Annals of Epidemiology 1999; 9: 178-87.

16 Schakel SF, Buzzard IM, Gebhardt SE. Procedures for estimating nutrient values for food composition databases. Journal of Food Composition and Analysis 1997; 10: 102-14.

17 Kristal AR, Shattuck AL, Williams AE. Food frequency questionnaires for diet intervention research. In: 17th National Nutrient Databank Conference. Baltimore, MD: International Life Sciences Institute, 1992; 110-25.

18 Patterson RE, Levy L, Fels-Tinker L, Kristal AR. Validity of a simplified vitamin supplement inventory procedure 
developed for the Women's Health Initiative. Public Health Nutrition 1999; 2: 273-6.

19 National Research Council, Committee on Diet and Health, Food and Nutrition Board, Commission in Life Sciences. Diet and Health: Implications for Reducing Chronic Disease Risk. Washington, DC: National Academy of Sciences, 1989.

20 Neuhouser ML, Patterson RE, Kristal AR, Rock CL, NeumarkSztainer D, Thornquist MD, et al. Do consumers of savory snacks have poor quality diets? Journal of the American Dietetic Association 2000; 100: 576-9.

21 The Expert Panel. Clinical guidelines on the identification, evaluation, and treatment of overweight and obesity in adults: executive summary. American Journal of Clinical Nutrition. 1998; 68: 899-917.

22 Raatz SK, Bibus D, Thomas W, Kris-Etherton P. Total fat intake modifies fatty acid composition in humans. Journal of Nutrition 2001; 131: 231-4.

23 Kohlmeier L. Biomarkers of fatty acid exposure and breast cancer risk. American Journal of Clinical Nutrition 1997; 66: $1548 \mathrm{~S}-56 \mathrm{~S}$.

24 Jiang Q, Christen S, Shigenaga MK, Ames BN. $\boldsymbol{\gamma}$-Tocopherol, the major form of vitamin $\mathrm{E}$ in the US diet, deserves more attention. American Journal of Clinical Nutrition 2001; 74: $714-22$.

25 Hu FB, Stampfer MJ, Manson JE, Ascherio A, Colditz GA, Speizer FE, et al. Dietary saturated fats and their food sources in relation to the risk of coronary heart disease in women. American Journal of Clinical Nutrition 1999; 70: 1001-8.

26 Cater NB, Denke MA. Behenic acid is a cholesterol-raising saturated fatty acid in humans. American Journal of Clinical Nutrition 2001; 73: 41-4.

27 Murphy SP, Rose D, Hudes M, Viteri FE. Demographic and economic factors associated with dietary quality for adults in the 1987-1988 Nationwide Food Consumption Survey. Journal of the American Dietetic Association 1992; 92: $1352-7$.

28 Glanz K, Basil M, Maibach E, Goldberg J, Snyder D. Why Americans eat what they do: taste, nutrition, cost, convenience, and weight control concerns as influences on food consumption. Journal of the American Dietetic Association 1998; 98: 1118-26.

29 Kristal AR, Patterson RE, Glanz K, Heimendinger J, Hebert JR, Feng Z, et al. Psychosocial correlates of healthful diets: baseline results from the Working Well Study. Preventive Medicine 1995; 24: 221-8.

30 Denke MA, Grundy SM. Comparison of effects of lauric acid and palmitic acid in serum lipid and lipoprotein levels. American Journal of Clinical Nutrition 1992; 56: 895-8.

31 Hann CS, Rock CL, King I, Drewnowski A. Validation of the Healthy Eating Index with use of plasma biomarkers in a clinical sample of women. American Journal of Clinical Nutrition 2001; 74: 479-86.
32 Fung TT, Rimm EB, Spiegelman D, Rifai N, Tofler GH, Willett WC, et al. Association between dietary patterns and plasma biomarkers of obesity and cardiovascular risk. American Journal of Clinical Nutrition 2001; 73: 61-7.

33 Gerber MJ, Scali JD, Michaud A, Durand MD, Astre CM, Dallongeville J, et al. Profiles of a healthful diet and its relationship to biomarkers in a population sample from Mediterranean southern France. Journal of the American Dietetic Association 2000; 100: 1164-71.

34 Armstrong BK, White E, Saracci R. Principles of Exposure Measurement in Epidemiology. Oxford: Oxford University Press, 1992.

35 Rock CL, Thornquist MD, Kristal AR, Patterson RE, Cooper D, Neuhouser ML, et al. Demographic and lifestyle variables differentially explain variability in serum carotenoids and fat-soluble vitamins: baseline results from the Olestra PostMarketing Surveillance Study. Journal of Nutrition 1999; 129: 855-64.

36 Brady WE, Mares-Perlman JA, Bowen P, StacewiczSapuntzakis M. Human serum carotenoids concentrations are related to physiologic and lifestyle factors. Journal of Nutrition 1996; 126: 129-37.

37 Yu S, Derr J, Etherton TD, Kris-Etherton PM. Plasma cholesterol-predictive equations demonstrate that stearic acid is neutral and monounsaturated fatty acids are hypocholesterolemic. American Journal of Clinical Nutrition 1995; 61: 1129-39.

38 Clandinin MT, Cook SL, Konard SD, French MA. The effect of palmitic acid on lipoprotein cholesterol levels. International Journal of Food Sciences and Nutrition 2000; 51: S61-71.

39 Kipnis V, Midthune D, Freedman LS, Bingham S, Schatzkin A, Subar A, et al. Empirical evidence of correlated biases in dietary assessment instruments and its implications. American Journal of Epidemiology 2001; 153: 394-403.

40 Kipnis V, Carroll RJ, Freedman LS, Li L. Implications of a new dietary measurement error model for estimation of relative risk: application to four calibration studies. American Journal of Epidemiology 1999; 150: 642-51.

41 Prentice RL. Measurement error and results from analytic epidemiology: dietary fat and breast cancer. Journal of the National Cancer Institute 1996; 88: 1738-47.

42 Prentice RL, Sugar E, Wang CY, Neuhouser ML, Patterson RE. Research strategies and the use of nutrient biomarkers in studies of diet and chronic disease. Public Health Nutrition 2002; 5: 977-84.

43 Kaaks RJ. Biochemical markers as additional measurements in studies of the accuracy of dietary questionnaire measurements: conceptual issues. American Journal of Clinical Nutrition 1997; 65: 1232S-9S.

44 Van het hof KH, West CE, Weststrate JA, Hautvast JG. Dietary factors that affect the bioavailability of carotenoids. Journal of Nutrition 2000; 130: 503-6.

45 Willett W. Nutritional Epidemiology, 2nd ed. New York: Oxford University Press, 1998. 